\title{
Real Academia Española: Libro de estilo de la lengua española según la normativa panhispánica. Madrid: Espasa (2018), 498 páginas. ISBN: 978-84-670-5379-1
}

\author{
Manuel José Aguilar Ruiz \\ Universitat de València
}

¿Se escribe PDF, pdf o .pdf? En los enunciados de los hashtags, ¿hay que escribir tilde en las palabras que la requieran, como en \#ÍñigoAsíNo? Un ofrecimiento del tipo Te invito a una $\odot$, escrito en una aplicación de mensajería instantánea como WhatsApp $\AA$, ¿debe cerrarse con un punto tras el emoji que termina el enunciado?

A finales de noviembre de 2018, la RAE publicó por primera vez un libro de estilo, el Libro de estilo de la lengua española según la norma panhispánica (en adelante, LELE), con la máxima notoriedad -como han señalado las diferentes notas de prensa que han reseñado la aparición del manual ${ }^{1}$ - de incluir apartados específicos sobre ortotipografía y escritura en medio digital, además de interesantes aspectos lexicográficos (como las recomendaciones generales para el aprovechamiento del diccionario académico o una avanzadilla de la próxima edición de este, de naturaleza digital).

De esta manera, la institución académica comienza a asentar, con carácter normativo, determinadas dudas cada vez más recurrentes, relativas a cuestiones ortotipográficas o a la escritura en soporte digital, que empezaron a plantearse pocos años atrás, con lo que las tres preguntas que comienzan la presente reseña quedan respondidas en la novedosa inclusión de dos capítulos (103 páginas en total) dedicados a dichas cuestiones² . Además,

1 Como en RAE, «Presentación del Libro de estilo de la lengua española» (en <http://www.rae.es/noticias/presentaciondel-libro-de-estilo-de-la-lengua-espanola>); CAMPS, Magí, «Se acabó escribir 'hacker' o 'pen drive', la RAE presenta su nuevo libro de estilo", La Vanguardia (en <https://www.lavanguardia.com/cultura/20181126/453186487020/se-acaboescribir-hacker-o-pen-drive-la-rae-presenta-su-nuevo-libro-de-estilo.html>); MARTín RODRIGO, Inés, «Un libro (de estilo) abierto para escribir y hablar como los ángeles", $A B C$ (en <https://www.abc.es/cultura/libros/abci-libro-estilo-abiertopara-escribir-y-hablar-como-angeles-201811270231 noticia.html>); MORALES, Manuel, «Wasap mejor que whatsapp: la RAE presenta su primer 'Libro de estilo' para "escritores digitales"», El País (en $<$ https://elpais.com/cultura/2018/11/26/actualidad/1543232021_887311.html >); etc.

${ }^{2}$ Así, mediante una rápida consulta al LELE, podríamos resolver las tres preguntas iniciales, y comprobaríamos que se escribe PDF, ya que en este caso coinciden en una sigla tanto el formato como el nombre del archivo (LELE, pág. 312); 
su naturaleza prescriptiva ratifica la normativa desde un ámbito decididamente panhispánico, admitiendo el carácter policéntrico del español, de forma que opta por soluciones que puedan resultar ampliamente aceptadas y válidas en todo el extenso ámbito hispanohablante (vid. LELE, págs. 14-15).

Dejando a un lado la «Presentación» (págs. 13-17) y la «Guía de uso de la obra» (págs. 1920) iniciales (que ofrecen instrucciones generales para el manejo y las claves interpretativas del libro mediante, por ejemplo, los distintos códigos referenciales para cada capítulo ${ }^{3}$ ) y los apéndices finales (págs. 475-498), la obra presenta dos partes bien diferenciadas: el manual propiamente dicho (págs. 21-334; 313 páginas en total) y un glosario (págs. 337474; esto es, 137 páginas).

1. El manual teórico, presentado en forma catequética de pregunta-respuesta, viene dividido en seis capítulos:

1.1. El capítulo primero (págs. 21-83), que según el código establecido por la obra emplea la letra $\mathrm{G}$ para su identificación, recopila en 62 páginas las dudas gramaticales más destacables y recurrentes en español, tematizándolas en las distintas categorías léxicas (verbos, pronombres, adverbios, preposiciones, determinantes, conjunciones, etc.) o centrándose en cuestiones problemáticas puntuales de algunas de ellas (género y número en la flexión nominal; sintagmas preposicionales con función de complemento directo introducidos por la preposición a; errores de concordancia entre sujeto-verbo o sustantivoadjetivo; usos indebidos en los que interviene o se elide la preposición de, conocidos como queísmo, dequeísmo y deísmo; empleos anómalos de pronombres personales átonos conocidos como laísmo y loísmo, además del leísmo indebido; etc.).

Así, por ejemplo, reafirma el masculino como el término no caracterizado de la oposición gramatical del género (pág. 21), de modo que no tiene sentido el pensamiento, extensamente generalizado, de que el género gramatical masculino no incluye a la mujer en enunciados del tipo Tengo cinco hijos; Buenos días a todos; Estimados alumnos, etc. De esta manera, los desdoblamientos del tipo Buenos días a todas y a todos o Estimados/as alumnos y alumnas, si bien innecesarios, serían una muestra de cortesía al comienzo de un discurso o en los saludos iniciales de una carta o de un correo electrónico, mientras que la prescripción académica rechaza otras fórmulas, como el símbolo de la arroba (@) o las grafías

igualmente, que las palabras que requieran acento gráfico o tilde no deben prescindir de ella en las etiquetas en redes sociales (excepto por causas de imposibilidad técnica), como se ha hecho correctamente en \#íñigoAsíNo (LELE, pág. 295), y que sí se debería escribir un punto con función demarcativa tras un emoji que sustituye una pieza léxica y cierra enunciado, como en Te invito a una D. (LELE, pág. 292).

${ }^{3}$ La parte del manual propiamente dicho, como se verá, está dividida en seis capítulos, a los que se les designa una letra o símbolo interpretativo (G para el capítulo sobre cuestiones gramaticales, $\mathrm{O}$ para las ortográficas, $\mathrm{T}$ para la ortotipografía, P para la pronunciación y entonación, @ para la escritura y comunicación digital y D para las orientaciones lexicográficas). A este se le suma un dígito que designa un apartado dentro de un capítulo, a lo que se le puede añadir una letra para indicar un subapartado. De esta manera, se puede conseguir un código bipartito o tripartito mediante el cual el glosario que conforma la segunda parte de la obra referencia el lugar exacto del manual en el que se detalla la información necesaria requerida para la consulta buscada (el lema del glosario). Este sistema referencial funciona también dentro del propio manual teórico. Así, por ejemplo, si consultamos en el glosario cuál sería la forma de plural del sustantivo té (¿tes o tés?), este nos remite, a través del código 0-63-a, al apartado número 63 del capítulo relativo a cuestiones ortográficas $(O)$, y en concreto al subapartado a, sobre observaciones particulares de la tilde diacrítica, y de ese modo comprobamos que la forma plural del sustantivo en cuestión conserva la tilde diacrítica (tés) del singular, con lo que es capaz de diferenciar gráficamente varias infusiones (tés) de varias letras (tes). 
-e- ০ -X- como seudomorfemas flexivos pretendidamente asexuados en escrituras como $\otimes / @ s$ niñ@s, $\otimes / e s$ niñes o $\otimes / x s$ niñxs.

Una de las novedades llamativas de esta sección, en las págs. 41-42, es la aceptación de la flexión iros como forma imperativa del verbo ir más el clítico os, cuya adición epentética de la -r- la hace coincidir con la forma infinitiva pro imperativa, desautorizada por la institución académica. Esta innovación, de julio de 2017, obviamente no había podido reflejarse aún en ninguna publicación impresa académica anterior con carácter normativo, como el DPD (2005), la NGLE (2009), la OLE (2010) o el DLE (2014), aunque sí apareció en forma de nota en la página web de la $\mathrm{RAE}^{4}$.

1.2. No presenta grandes innovaciones el capítulo segundo, dedicado a cuestiones ortográficas, que se identifica con la letra $\mathrm{O}$-siguiendo la nomenclatura del manual- y se extiende desde la página 85 hasta la 147 (62 páginas). En él se recopilan las dudas más frecuentes relativas a cuestiones ortográficas, ya comentadas en obras anteriores, tanto académicas, como el DPD, la NGLE, la OLE, el DLE, la propia RAE mediante el Departamento de «Español al día» ${ }^{5}$ en su página web o a través de su Twitter ${ }^{6}$, etc., como no académicas pero también con carácter "oficial», como El libro del español correcto (2012) o Las 500 dudas más frecuentes del español (2013), ambas del Instituto Cervantes, o las publicaciones en línea de la Fundéu, tanto digitales (en su página web ${ }^{7}$ ) como impresas (por ejemplo, su Manual de español urgente, de 2015). En este capítulo, pues, se repasa la normativa general relativa, entre otras cuestiones, a las grafías que pueden resultar problemáticas (págs. 85100) o a las principales dudas sobre acentuación (págs. 100-107), puntuación (págs. 107132), mayúsculas (págs. 134-141), distintos tipos de abreviaciones y cuestiones de escritura braquigráfica, como abreviaturas, siglas y símbolos (págs. 141-143), extranjerismos (págs. 143-144) y expresiones numéricas (págs. 144-147), sin el mismo nivel de profundidad -sin duda por problemas de espacio y por la propia concepción del manual- con la que se resuelven estas mismas dudas en otras publicaciones académicas, como en la OLE.

Así, en el breve apartado relativo a la escritura de porcentajes (pág. 147), se explica que, si se opta por la escritura en cifra de la expresión del porcentaje, será usual acompañarla con el símbolo \%, el cual, como todos los símbolos pospuestos, ha de separarse de su cifra mediante un espacio en blanco. Sin embargo, este manual no llega a profundizar en casos más específicos, como aquellos en los que la expresión de porcentaje consiste en una coordinación de dos cifras (en enunciados del tipo entre el $20 \%$ y el $25 \%$ o en la unión de ambas mediante un guion (en $20-25 \%$, por ejemplo), que tienen soluciones diferentes (la primera, repitiendo el símbolo detrás de cada cifra, y la segunda, sin necesidad de duplicarlo tras la primera), como aclara la OLE (pág. 698). De la misma manera, como hace la misma OLE (pág. 666), considera válidos tanto la coma como el punto como separador decimal, dependiendo del ámbito geográfico hispánico (de forma que sería correcto tanto 3,14 como 3.14 para expresar el número pi); sin embargo, el manual no recuerda la recomendación ortográfica académica (OLE, pág. 666) del uso del punto como signo

\footnotetext{
4 En RAE, «Nota sobre la aceptación de iros como forma de imperativo de 2. ${ }^{\text {a }}$ pers. plural» (en $<$ www.raeinforma.com/rae-content/uploads/2017/07/\%C2\%ABIros\%C2\%BB-imperativo-1-1.pdf $>$.).

5 En $<$ http://www.rae.es/consultas-linguisticas/preguntas-frecuentes $>$.

${ }^{6}$ En $<$ https://twitter.com/RAEinforma $>$.

${ }^{7}$ En $<$ https://www.fundeu.es/ $>$.
} 
preferible para este uso, para favorecer un proceso que tienda hacia la unificación en el ámbito hispanohablante.

Tampoco resulta tan taxativa, respecto a la redacción equivalente en la OLE (pág. 269), la redacción en el LELE (pág. 103) referida a las instrucciones de prescindir de la tilde en el adverbio solo o en los pronombres demostrativos. En efecto, mientras que en la Ortografía de 2010 se optó, de una forma algo más categórica, por prescindir de ella en estas voces, «incluso en casos de doble interpretación» (OLE, pág. 269) ${ }^{8}$, sin embargo, ahora en el LELE simplemente se recomienda no tildarlos nunca (esto es, no pasa de ser una recomendación), reconociendo que la tilde se podría admitir en casos en los que haya riesgo de ambigüedad.

Las innovaciones más destacables y lo que aporta mayor notoriedad a la obra aparece en los cuatro capítulos restantes.

1.3. Así, el capítulo tercero, identificado con la letra T en la nomenclatura del manual, está dedicado a cuestiones ortotipográficas. Si bien no es la primera ocasión en que la academia pretende establecer normativa sobre estas cuestiones (pues ya se realizaron unas primeras incursiones en las ortografías académicas de 1999 y sobre todo de 2010, con valoraciones dispares por parte de estudiosos como Martínez de Sousa ${ }^{9}$ o Bezos López ${ }^{10}$, por ejemplo), ahora sí se dedica, por primera vez en una publicación de la RAE, un apartado exclusivo a la ortotipografía, como destaca el propio manual (LELE, pág. 15).

El capítulo supone un total de 60 páginas (desde la 149 hasta la 209) centradas en interesantes cuestiones ortotipográficas como, por ejemplo, aspectos relativos a la configuración de la página (págs. 175-183), tanto de su caja (la disposición en párrafos, en columnas, los distintos tipos de párrafo, etc.) como de sus blancos (márgenes, sangrías, etc.), además de otros elementos importantes que se han de tener en cuenta en la autoedición de textos (encabezados, pies de página, control de líneas viudas y huérfanas, interlineado, numeración de la página, etc.). Introduce al lector en conceptos muy específicos de autoedición, como las opciones del kerning y tracking (LELE, pág. 172), el espacio de no separación (por ejemplo, para respetar la normativa académica del espacio en blanco como separador de millares sin el riesgo de separar la cifra en dos líneas distintas) o los caracteres especiales, imprimibles y no imprimibles (págs. 169-171), que suelen venir por defecto en procesadores de texto como OpenOffice Writer ${ }^{\mathrm{TM}}$ o Microsoft Word $®$ (como el guion opcional, el guion de no separación, el salto de línea, el salto de párrafo, el salto de columna, el salto de sección, etc.), elementos paratextuales como la titulación (págs. 183-196), cuadros, tablas, ilustraciones y figuras (págs. 186-188), etc.

Aparte de una detallada sección (págs. 150-168) en la que se desarrolla ampliamente el uso de tipos de letra, como la cursiva, la redonda, la versalita y la negrita, además de las letras en

\footnotetext{
${ }^{8}$ Hecho que se sigue reconociendo en la misma página web de la RAE, en el título «El adverbio solo y los pronombres demostrativos, sin tilde", dentro del apartado de «Preguntas frecuentes» inserto en las "Consultas lingüísticas" del Departamento de «Español al día» (en <http://www.rae.es/consultas/el-adverbio-solo-y-los-pronombresdemostrativos-sin-tilde $>$ ).

9 Vid. «La "nueva" ortografía académica» (en <http://www.martinezdesousa.net/nuevaorto-academia.pdf>); «La ortografía académica del 2010: cara y dorso" (en <http://www.martinezdesousa.net/crit_ole2011.pdf>).

10 Vid. «Las notaciones científicas en la Ortografía académica» (en <http://www.texnia.com/ortografia_notaciones.html>).
} 
superíndice y en subíndice (cuyas instrucciones generales ya se apuntaban en la OLE), se dedican cuatro secciones -muy valiosas para la práctica docente en el ámbito académico y universitario- en las que se aclaran pormenorizadamente aspectos útiles centrados en la elaboración de textos de naturaleza formal y académica, relacionados con el sistema de remisiones intratextuales (págs. 188-190), las llamadas y notas a pie de página (págs. 195198), la configuración de citas textuales en el texto (págs. 190-195) y la confección de referencias bibliográficas (págs. 198-209).

1.4. El capítulo cuarto (págs. 211-267) está dedicado a aspectos orales de la lengua, y queda identificado con la letra $P$, según el sistema de códigos referenciales establecido por la publicación. Se dedica, a lo largo de sus 56 páginas, a hechos fonológicos y de índole suprasegmental relacionados con la pronunciación y la elocución, como revela su título. El primer apartado, «Pronunciación», revisa diversos problemas relativos a la pronunciación de fonemas, grafías, encuentros vocálicos y secuencias consonánticas. Así, analiza las diferencias del carácter mudo o aspirado de la letra h (pág. 213); la pronunciación como /s/ tanto de la $x$ - inicial en voces como xilófono (pág. 214) como del grupo ps- inicial en psicología o psoriasis, incluso en las pronunciaciones más cuidadas (pág. 220); la distinta percepción como diptongos o hiatos en encuentros vocálicos de guion, piano, jesuita o Joaquín (págs. 215-216) o la imposibilidad gráfica de escribir en español la combinación del imperativo del verbo salir (sal) y en pronombre enclítico le, debido a la obligada pronunciación de la secuencia de doble ele como el dígrafo II (pág. 219) ${ }^{11}$.

1.5. El capítulo quinto, que ocupa las páginas 269-312 (un total de 43) y se identifica con el símbolo de la arroba (@), versa sobre la «Escritura y comunicación digital», como indica su título, y ofrece, pues, algunas directrices sobre la escritura correcta en textos digitales en general, como la recomendación de redactar enunciados cortos, precisos y claros, con palabras sencillas y estructuras comprensibles, hecho que asegurará, por ejemplo, una buena traducción automática en caso de que se necesite (por ejemplo, en Twitter; pág. 275). Para ello, indica que se deben respetar las normas generales del español, aunque este tipo de escritura se encuentra muy cerca de la oralidad (pág. 271), y reafirma la idea de que una escritura electrónica efectiva ha de ser capaz de emplear las múltiples posibilidades que ofrece la escritura digital (hipervínculos, elementos de naturaleza visual como imágenes, vídeo o emojis, etc.; pág. 270), siendo conscientes de que nuestra escritura se convertirá en pública (pág. 272). Aporta recomendaciones sobre el uso de la almohadilla (págs. 296-297), menciones y etiquetas (págs. 295-296), el empleo de abreviaturas (pág. 285), iconos, emoticones y emojis (págs. 290-293), hipervínculos (págs. 293-295), memes (pág. 293), etc., e indicaciones particulares sobre distintos canales, como el correo electrónico (págs. 297-299), las páginas web (págs. 299-300), los blogs (pág. 300-301), los chats y otros sistemas de mensajería instantánea (pág. 306), las redes sociales (págs. 306308), etc., algunos ya adelantados por el Instituto Cervantes en El libro del español correcto (de 2012, en las págs. 459-484). Termina (págs. 310-312) con una breve normativa sobre la ortografía de la nomenclatura de los medios digitales (nombres de redes sociales, títulos de blogs, nombres de directorios, carpetas, archivos, formatos y extensiones de archivos), etc.

1.6. El capítulo sexto, de carácter lexicográfico, está identificado con la letra $D$ y se titula "Cómo aprovechar el diccionario". Se extiende 21 páginas, desde la 313 hasta la 334 , y puede dividirse en dos partes claramente diferenciadas. La primera estaría constituida por las

\footnotetext{
11 Imposibilidad que ya recogía la normativa académica en la OLE (pág. 174).
} 
secciones «El Diccionario de la lengua española (DLE)» (págs. 313-325) y «Otros diccionarios académicos» (págs. 325-327), y en ellas se ofrecen consejos e instrucciones muy precisas sobre la labor de búsqueda en el diccionario académico (voces que a priori no aparecerán o sí en la macroestructura del diccionario, las diversas marcas lingüísticas empleadas, como las diatópicas, diacrónicas, diafásicas, gramaticales, etc.) y una breve reseña del Diccionario de americanismos y del Diccionario del estudiante, otras dos obras lexicográficas académicas de carácter específico.

La segunda parte, «Hacia un diccionario digital panhispánico», está dividida en dos secciones. En la primera de ellas, «El presente» (págs. 327-331), se describe brevemente las características esenciales de la versión digitalizada de la edición actual del diccionario académico (gran legibilidad y navegabilidad, policromía, repetición de las informaciones relevantes, como las gramaticales, desarrollo automático de las abreviaturas, autocompletado y posibilidades en la casilla de búsqueda, paradigma de conjugación completa de verbos, etc.). La segunda sección, «El futuro» (págs. 331-334), constituye una gran innovación, al suponer un adelanto de cómo será la próxima edición del diccionario académico. Algunas de las novedades más destacables que adelanta, consecuencia directa de su concepción digital -muchas de ellas impensables en un diccionario tradicional impreso, con sus múltiples convenciones destinadas a ahorrar espacio-, son la mayor presencia de voces americanas, como reflejo de la realidad policéntrica del español; una gran posibilidad de distintos niveles de visualización de los artículos lexicográficos, con versiones esquematizadas o enriquecidas; el menor número de abreviaturas y de otros procedimientos lexicográficos concebidos para ahorrar espacio impreso, como las definiciones recursivas o «emparentadas» ${ }^{12}$ o las definiciones sinonímicas; la posibilidad de inclusión de abundante información ortográfica, morfológica, sintáctica, semántica y pragmática, así como de ejemplos de uso y de reproducciones de pronunciación; los hipervínculos a los corpus (el CORDE ${ }^{13}$ o el CORPES $X X I^{14}$, por ejemplo) y a otras publicaciones académicas (como la $O L E^{15}$ o la $N G L E^{16}$ ); la inclusión de la fecha de la primera aparición del lema consultado, con información estadística sobre la frecuencia de este o una lista de sus sinónimos, voces afines y antónimos (o de sus acepciones), a la vez que las combinaciones en las que suele aparecer habitualmente; etc.

2. Fuera del manual en sí, la segunda gran parte en la que se divide la publicación académica aquí reseñada es un copioso glosario de dudas, de especial relevancia porque supone el «germen y compendio» (pág. 16) de la obra. Comprende las págs. 337-474 (137 páginas en total), y en él se lematizan dos tipos distintos de entradas. Por un lado, presenta en letras mayúsculas aquellos lemas que constituirían un índice temático, de manera que el consultante que desee aclarar cuestiones generales y globales (como, por ejemplo, dudas sobre el uso de las mayúsculas o las abreviaturas) puede buscar cualquiera de estos lemas (MAYÚSCULAS o ABREVIATURAS), y en ellos se remite a los capítulos y apartados en los que se explica detalladamente los usos consultados, mediante la combinación de los códigos identificadores G, D, T, etc. y dígitos, que ya se ha comentado. Por otro lado, el glosario está concebido también como un léxico de dudas, en el que pueden consultarse

\footnotetext{
${ }^{12}$ Como los esquemas definitorios para las voces derivadas por el sufijo -ción como 'Acción y efecto de + base verbal'.

${ }^{13}$ En $<$ http://corpus.rae.es/cordenet.html>.

${ }_{14} \mathrm{En}<\mathrm{http}: / /$ www.rae.es/recursos/banco-de-datos/corpes-xxi $>$.

${ }^{15}$ En <http://aplica.rae.es/orweb/cgi-bin/buscar.cgi >.

${ }^{16}$ En <http://aplica.rae.es/grweb/cgi-bin/buscar.cgi $>$.
} 
lemas que ofrezcan alguna dificultad de índole ortográfica ${ }^{17}$, gráfica ${ }^{18}$, prosódica $^{19}$, ortotipográfica $^{20}$, morfológica ${ }^{21}$, sintáctica ${ }^{22}$, etc.

En el glosario, además, puede hallarse un buen número de las propuestas de adaptación de extranjerismos. Algunas ya fueron aceptadas con anterioridad por la institución académica (por ejemplo, en 2014, a través del DLE, o de las dos actualizaciones que este ha experimentado, en 2017 y 2018, publicadas digitalmente en la misma página web de la Academia), pero otras aparecen como meras propuestas de adaptación. Pueden causar sorpresa al consultante, a pesar de estar ya aceptadas, las grafías $j i p i^{23}$ para hippie/hippy, tableta ${ }^{24}$ para tablet o $z \mathrm{um}^{25}$ para zoom, o el mantenimiento como extranjerismo no adaptado (por su escritura en letra cursiva) de pizza ${ }^{26}$, mientras que otras voces relativas a comidas foráneas y de incorporación relativamente reciente, como hummus/humus ${ }^{27}$ o $k e b a b^{28}$ se presentan plenamente aceptadas, con escritura en redonda ${ }^{29}$.

De entre las propuestas de adaptación o alternativas preferibles adelantadas por el manual (si bien algunas de ellas ya han aparecido con anterioridad en la web de la Fundéu, que puede tomarse como un instrumento para evaluar el grado de aceptación de estas por parte

\footnotetext{
17 Por ejemplo, cuándo el préstamo adaptado alzhéimer se emplea con mayúscula inicial y sin acento gráfico (es decir, Alzheimer, en la pág. 346, remitiendo a su explicación en la pág. 138); si es correcta la grafía y pronunciación esdrújula Éverest (pág. 391) o por qué el participio construido no lleva tilde, pero traído sí (pág. 339, remitiendo a las págs. 100 y ss. mediante el código O-60-d).

${ }_{18}$ Por ejemplo, si es preferible la escritura como locución adverbial en seguida o como pieza léxica adverbial soldada gráficamente enseguida (pág. 387), o qué diferencia existe entre sobretodo y sobre todo (pág. 456).

19 Por ejemplo, por qué la /i/ es tónica y lleva acento gráfico en el plural especímenes, pero no es así en su correspondiente singular espécimen (pág. 389, remitiendo a la pág. 26 y, en concreto, a la referencia G-15-a).

20 Por ejemplo, qué es el interletraje y qué la interlínea (pág. 409, remitiendo, erróneamente, a las págs. 170 y 176-177 mediante los códigos T-28 y T-49, cuando estos conceptos se tratan realmente en las págs. 172 y 180 , con los códigos T-39 y T-60); si las locuciones a priori y a posteriori han de escribirse con letra cursiva (pág. 349) o, por el contrario, con letra redonda, como in fraganti (pág. 408).

${ }^{21}$ Por ejemplo, la posibilidad del femenino elefanta (págs. 22 y 385), la forma gais como plural de gay (pág. 397), la conjugación del verbo abolir (pág. 337, remitiendo a la pág. 34 mediante el código G-40-e) o el género del sustantivo Internet (¿la o el Internet?, pág. 409, remitiendo para su explicación a la pág. 25 mediante el código G-13).

22 Por ejemplo, para concretar las preposiciones exigidas por un verbo determinado para introducir su régimen verbal, como reírse de y reírse con (pág. 448), o qué preposición se construye con el verbo vigilar con el sentido de 'velar' (pág. 469).

23 'Dicho de un movimiento: De carácter contracultural y juvenil, surgido en los Estados Unidos de América en la década de 1960 y caracterizado por su pacifismo y su actitud inconformista hacia las estructuras sociales vigentes'; 'Perteneciente o relativo al movimiento jipi'; 'Partidario del movimiento jipi' (DLE, s. v. jipi).

24 'Dispositivo electrónico portátil con pantalla táctil y con múltiples prestaciones' (DLE, s. v. tableta).

25 'Objetivo de distancia focal variable, que modifica el ángulo de visión con el efecto de acercar o alejar la imagen' (DLE, s. v. zum).

26 'Especie de torta de harina amasada, encima de la cual se pone queso, tomate frito y otros ingredientes, y que se cuece en el horno' (DLE, s. v. pizza).

27 'Pasta de garbanzos, típica de la cocina árabe, aderezada generalmente con aceite de oliva, zumo de limón, crema de sésamo y ajo' (DLE, s. v. hummus).

28 'Masa de carne picada que, ensartada en una varilla, se asa haciéndose girar ante una fuente de calor' (DLE, S. V. kebab).

${ }^{29}$ La escritura con cursiva de la pieza léxica pizza sería atribuible, tal vez, al encuentro consonántico anómalo en español de dos -zz- en posición interior, aunque la variante hummus se ha resuelto con escritura en redonda aun presentando un encuentro interior de consonantes geminadas similar al de pizza, o a pesar de la grafía también en redonda de kebab, por más que presente una terminación en - $b$, no contemplada por la fonotaxis del español. No obstante, este mantenimiento de la voz pizza como extranjerismo no adaptado origina, comparado con voces derivadas de ella (como pizzería o pizzero), una incongruencia gráfica, ya que las voces derivadas de pizza pasan a considerarse, como derivadas que son (pues se han originado mediante un procedimiento interno de sufijación) piezas léxicas españolas, por lo que se escriben ya en letra redonda, aun con la anómala grafía de doble -zz-.
} 
de los hablantes), podrían destacarse las voces cheslón ${ }^{30}$ (por chaise longe), destripe ${ }^{31}$ (por spoiler), estríper ${ }^{32}$ (por stripper), jáquer ${ }^{33}$ (por hacker), rali ${ }^{34}$ (por rally), wasap/guasap ${ }^{35}$ y sus respectivos verbos wasapear/guasapear ${ }^{36}$ (por WhatsApp), yintónic ${ }^{37}$ (por la ya adaptada como gin-tonic en el $D L E$ ) o yutubero ${ }^{38}$ (por youtuber). Entre las propuestas de inclusión o aceptación de nuevas voces, se podrían destacar faláfel/falafe $\beta^{39}$ y simpa ${ }^{40}$ o las siglas $\mathrm{DOI}^{41}$ y URL ${ }^{42}$.

3. Los cinco apéndices finales (págs. 475-498) recogen material ya publicado anteriormente también como coda en diversas obras académicas (el DPD, la NGLE, la OLE, el $D L E$, etc.) y en la página web de esta, como son los modelos de conjugación verbal (solo los tres modelos de verbos regulares), una tabla con los distintos numerales (cardinales, ordinales, fraccionarios y multiplicativos) y las listas de abreviaciones más destacables, distinguiendo entre las abreviaturas y los símbolos alfabetizables y los no alfabetizables.

4. De manera general, se puede valorar la obra ratificando que mientras que los capítulos primero y segundo del manual suponen quizá poca novedad, ya que son un breve compendio de las dudas gramaticales y ortográficas más frecuentes en español (tratadas con mayor extensión y profundidad en otras publicaciones anteriores, tanto académicas como realizadas por parte del Instituto Cervantes o la Fundéu), sí presentan cierta notoriedad los cuatro capítulos restantes, junto con el glosario. Sin embargo, una parte de las inclusiones que se pueden presentar como absolutas innovaciones hay que considerarlas como tales en su justa medida. Por ejemplo, la idea académica de la publicación de un libro de estilo no es nueva, sino que ya venía rondando diecisiete años atrás, desde $2001^{43}$; tampoco supone una completa novedad la inclusión de cuestiones puramente ortotipográficas, que la Academia viene aportando paulatinamente en las ortografías anteriores (aunque de manera no tan global y sin dedicarles un capítulo individual, como sucede aquí en la obra reseñada). Además, cuestiones sobre la pronunciación y elocución o recomendaciones sobre los nuevos tipos de escrituras en soporte digital también se han ido tratando progresivamente por parte del Instituto

\footnotetext{
30 'Sofá sin respaldo ni brazos y que también sirve para tumbarse' (LELE, pág. 366).

31 'Anticipo o adelanto del desenlace o de una parte de la trama de una película, un relato de ficción o una declaración, que resta interés por la resolución final' (LELE, pág. 389).

32 'Persona que se dedica profesionalmente a desnudarse en público' (LELE, pág. 391).

33 'Persona con grandes habilidades en el manejo de computadoras, capaz de utilizar sus conocimientos para piratear sistemas informáticos'; 'Persona experta en el manejo de computadoras, que se ocupa de la seguridad de los sistemas y de desarrollar técnicas de mejora' (LELE, pág. 402).

34 'Competición de resistencia, de automóviles o de motocicletas, celebrada fuera de pista y generalmente por etapas' (LELE, pág. 446).

35 'Mensaje enviado por la aplicación de mensajería instantánea WhatsApp®' (LELE, pág. 470).

36 'Intercambiar mensajes por WhatsApp®' (LELE, pág. 470).

37 'Bebida alcohólica compuesta de ginebra y tónica' (LELE, pág. 473).

38 'Persona que sube vídeos a YouTubeß' (LELE, pág. 473).

39 'Plato típico de la cocina árabe y del Oriente Medio en forma de croqueta' (LELE, pág. 394).

40 Con la acepción de 'Salida de un establecimiento sin pagar' (LELE, pág. 455), que coincide con un americanismo homónimo ('Trenza hecha con cualquier material, y especialmente con el cabello', DLE), procedente del quechua.

41 'Identificador permanente asignado a un recurso digital' (LELE, pág. 382).

42 'Identificador de la dirección que permite localizar los documentos y recursos de información disponibles en Internet' (LELE, pág. 466).

${ }^{43} \mathrm{RAE}$, «Presentación del Libro de estilo de la lengua española» (en <http://www.rae.es/noticias/presentacion-del-librode-estilo-de-la-lengua-espanola>); MARTín RODRIGo, Inés, «Un libro (de estilo) abierto para escribir y hablar como los ángeles", $A B C$ (en <https://www.abc.es/cultura/libros/abci-libro-estilo-abierto-para-escribir-y-hablar-como-angeles201811270231 noticia.html $)$.
} 
Cervantes o de la Fundéu (como por ejemplo en Saber hablar, de 2008, o El libro del español correcto, de 2012, ambas del Instituto Cervantes), cuando no por parte de la misma institución académica. No obstante, resulta verdaderamente destacable que la Academia, a través de la inclusión de estas en un manual de carácter oficial como es el LELE, comienza a atribuir naturaleza normativa a algunas de las novedades referidas a soluciones ortotipográficas y prácticas de escritura de textos electrónicos, por ejemplo. Este hecho evidencia los enormes esfuerzos de la institución académica por intentar aportar soluciones prescriptivas a hechos ortotipográficos específicos a los que se han de hacer frente desde la autoedición o a tipologías tan recientes como las relativas a la escritura digital, y todo ello desde un punto de vista panhispánico y decididamente policéntrico.

Por otro lado, el método de referencias internas de la obra mediante los consabidos códigos bi- o tripartitos puede resultar tal vez poco intuitivo. Al consultante medio quizá podría resultarle más fácil la mera indicación de la página; también podría resultar algo menos confuso el procedimiento de la mención directa de capítulos y párrafos empleado en otras publicaciones académicas, como la OLE o la NGLE. Sin embargo, el deseo de actualización, de difusión y de llegar a conectar con público más amplio y joven, usuario de redes sociales y de medios de comunicación digitales, se evidencia al afrontar decididamente determinados problemas del español actual ${ }^{44}$ y en la selección de buen número de los ejemplos ilustrativos a lo largo de la obra ${ }^{45}$. Además, consta el deseo de disponer de una versión en línea de la obra ${ }^{46}$, lo que la hará más fácilmente accesible y facilitará su difusión. En definitiva, el LELE resulta un manual totalmente recomendable no solo para los profesionales del español, sino para cualquier hispanohablante que ame su lengua, sienta curiosidad por ella y desee conocerla y expresarse en ella mejor.

\footnotetext{
${ }^{44}$ Como lo relativo a la cuestión del género gramatical en las págs. 21-26, por ejemplo; vid. SEISDEDOS, Iker, «Darío Villanueva: "El problema está en confundir la gramática con el machismo"», El País (en $<$ https://elpais.com/cultura/2018/07/15/actualidad/1531677196_003986.html>).

45 Como los Javis como ejemplo denominaciones en plural de personas (pág. 138) o el titular Cristiano Ronaldo, a la Juventus para ilustrar el uso de la coma por omisión verbal en los titulares del lenguaje periodístico (pág. 301), entre muchos otros.

${ }^{46}$ Vid. MORALES, Manuel, «Wasap mejor que whatsapp: la RAE presenta su primer 'Libro de estilo' para "escritores digitales"», El País (en <https://elpais.com/cultura/2018/11/26/actualidad/1543232021_887311.html>).
} 